\title{
I maginando una nueva industria de los hidrocarburos para el Perú: una mirada "no convencionar" y alternativa al sector
}

\author{
Eduardo Ramos *
}

En el presente artículo, el Dr. Eduardo Ramos realiza un análisis sobre las implicancias de una nueva industria de los hidrocarburos para el Perú, su situación actual y el impacto de los hidrocarburos en la seguridad energética y economía del país.

* Asociado Senior de Rodrigo, Elías \& Medrano Abogados. Abogado por la Facultad de Derecho de la Universidad de Piura. Expositor en el curso de Derecho de la Minería y Energía de la Facultad de Derecho de la Pontificia Universidad Católica del Perú. Ha sido ponente en el Curso de Extensión Universitaria en Regulación de Servicios Públicos con Especialización en Energía y Minería - OSI NERGMIN.

** El autor desea agradecer a Ximena Calderón, asociada de Rodrigo, Elías \& Medrano Abogados por su colaboración en la elaboración del presente artículo. 
Imaginando una nueva industria de

hidrocarburos para el Perú: una mirada

"no convencional" y alternativa del sector.

\section{I maginando una nueva industria de los hidrocarburos para el Perú: una mirada "no convencional" y altemativa al sector.}

\section{Introducción}

La dramática caída en los precios internaciones del barril de petróleo ha demostrado que la industria petrolera global ha llegado a un punto posiblemente irreversible, lo cual a nuestro juicio ha sido ocasionado por diversos factores: (i) económicos: consistentes, por un lado, en la mayor producción de países no miembros de la Organización de Países Exportadores de Petróleo (OPEP) como Rusia y de los Estados Unidos de América (shale boom) y, por otro lado, la contracción de la demanda de los países industrializados por su bajo crecimiento económico (por ejemplo, China) o por haber desarrollado programas de eficiencia energética; (ii) políticos: la voluntad de Arabia Saudita (mayor productor mundial) -y de otros países no pertenecientes a la OPEP (por ejemplo, Rusia)- de no reducir su producción diaria de petróleo en respuesta o como castigo a países productores como Irán, Venezuela y la misma Rusia; y, (iii) ambientales: los compromisos de países desarrollados de reducir sus emisiones contaminantes al medio ambiente.

Si los factores antes indicados continúan inalterables, entonces el período de precios internacionales bajos continuará. Esta situación favorece a países como el Perú, cuya balanza comercial de hidrocarburos es deficitaria y por eso debe importar aproximadamente 140 mil barriles diarios de este recurso natural. Hasta la fecha, aún es incierto el plazo en que el precio del petróleo va a alcanzar un nuevo equilibrio, ni cuál sería el precio que alcanzaría. Mientras tanto, como explicaremos en el presente artículo, consideramos que éste es el momento perfecto o "período de transición " para tomar decisiones importantes en nuestra industria de hidrocarburos.

La industria de hidrocarburos no es un ámbito nuevo en nuestro país, es una industria que tiene más de 150 años. No solamente destacamos su historia en este artículo, sino también hacemos énfasis de su rol e impacto en nuestra realidad política y económica, especialmente en los siguientes aspectos fundamentales: (i) nuestra seguridad energética; y, (ii) el crecimiento económico.

Pese a ello, en la actualidad, este sector está experimentando una cruda realidad que se ve reflejada principalmente en una producción declinante de petróleo crudo. En palabras simples, el Perú está produciendo menos petróleo del que consume. Por este motivo, además de identificar las principales trabas que enfrenta la industria de hidrocarburos, planteamos una mirada "no convencional" y alternativa que busca alcanzar un doble objetivo: (i) eliminar los principales problemas que enfrentan las empresas petroleras con contratos de hidrocarburos suscritos; y, (ii) presentar soluciones alternativas a aspectos en la regulación de la industria, que tienen por finalidad atraer una mayor cantidad de inversionistas. 
Atendiendo a lo expuesto, en el acápite II del presente documento presentamos una breve descripción de la historia y la regulación de la industria de hidrocarburos en el Perú. Luego, en el acápite III nos enfocamos en la importancia e impacto de esta industria en el desarrollo del Perú y su preocupante situación actual por diversos factores. Posteriormente, en el acápite IV enumeramos las trabas más significativas que enfrentan las empresas petroleras en el Perú y, en línea con lo anterior, en el acápite $\mathrm{V}$ presentamos nuestra visión y propuesta "no convencional" y alternativa que buscan promover el desarrollo de la industria de hidrocarburos en el corto, mediano y largo plazo. Finalmente, recogiendo todo lo anterior, en el acápite VI planteamos las conclusiones hacia las cuales nos encausa el presente artículo.

\section{Breve historia de la industria de hidrocarburos en el Perú: más de $\mathbf{1 5 0}$ años y necesitamos seguir contando'.}

La actividad de hidrocarburos en el Perú, una de las más dinámicas en nuestra historia y un driver importante en la economía nacional, se inició en el año 1863 en la localidad de Zorritos (Tumbes) con los primeros trabajos en el denominado "Pozo N 4". Dicho pozo perolero se constituyó en el primero en Sudamérica y el segundo a nivel mundial. Desde sus inicios, principalmente, sería el capital de empresas extranjeras y su organización los responsables de llevar a cabo las actividades petroleras ${ }^{2}$.

A nuestro juicio, la historia de los hidrocarburos ya ha sido ampliamente estudiada en nuestro medio, pero no podemos descartar nuevas investigaciones que permitan clarificar aspectos aún oscuros o revisar otros que actualmente están meridianamente claros.

En las últimas décadas, nuestro marco legal en materia de hidrocarburos ha experimentado modificaciones significativas y de forma pendular, las cuales pueden resumirse en los siguientes hitos: (i) Transición de un sistema de concesiones tradicional (1952) a un régimen de servicios públicos (1969); y, (ii) Transición de un régimen de servicios públicos (1969) a un sistema contractual (1993), actualmente vigente.

En cuanto a la normativa que rige actualmente las actividades de hidrocarburos, consideramos que éstas pueden agruparse de la siguiente manera:

1 Para la elaboración de esta sección se ha considerado el siguiente artículo: Larry B. Pascal, "Re-Opening the Genie's Bottle - The Peruvian Oil and Gas Market". En: Latin American Law and Business Report, Vol 21, Número 6, Junio 2013, en el cual el autor contribuyó para su elaboración.

2 Así fue desde el principio, no obstante que el primer pozo fue abierto por dos socios locales de la provincia de Talara. Cfr. Noriega Calmet, Fernando, "Historia de la Industria del Petróleo en el Perú desde sus comienzos hasta la fecha". Publicado en: http://www.osinerg.gob.pe/newweb/pages/GFH/1642.htm. 
Imaginando una nueva industria de hidrocarburos para el Perú: una mirada "no convencional" y alternativa del sector.

\subsection{Reglas de Primera Generación: Ley Orgánica de Hidrocarburos y sus normas reglamentarias.}

En primer lugar, las actividades de hidrocarburos se rigen por la Ley 26221, que aprueba la Ley Orgánica de Hidrocarburos ("LOH") ${ }^{3}$, emitida en 1993. A casi veintidós años desde su publicación, la LOH nos ofrece una especial atención, ya que desarrolla la estructura legal básica que actualmente gobierna tanto las actividades "aguas arriba" (upstream) como las actividades "aguas abajo" (downstream) del sector hidrocarburos.

En el contexto político y económico de los años en que fue publicada (luego de la disolución del Congreso en 1992), consideramos que la finalidad de la LOH fue -y claramente al día de hoy lo sigue siendo- básicamente: (i) proporcionar las garantías legislativas ("reglas de juego") a la inversión en materia de hidrocarburos; y, (ii) fomentar la competencia en la producción y comercialización de hidrocarburos.

En términos más sencillos, la LOH y sus normas reglamentarias establecen las "reglas de juego" legales, económicas y técnicas, aplicables al desarrollo de la industria de hidrocarburos.

\section{(i) Reglas del "Upstream": exploración y explotación}

Los hidrocarburos in situ son propiedad del Estado, de conformidad con la LOH. Cualquier persona natural o empresa privada o pública, nacional o extranjera, podrá llevar a cabo actividades de exploración y explotación de dichos recursos previa suscripción de un contrato de hidrocarburos con el Estado, representado por PERUPETRO S.A. ("PERUPETRO"). Para tales efectos, la LOH le ha transferido a PERUPETRO el derecho de propiedad sobre los hidrocarburos extraídos.

El otorgamiento de los derechos de hidrocarburos podrá ser realizado a través de cualquiera de las siguientes modalidades contractuales: (i) Contrato de Licencia, en mérito del cual se transfiere el derecho de propiedad de los hidrocarburos extraídos a la empresa petrolera, quien debe pagar una regalía al Estado; (ii) Contrato de Servicios, por medio del cual el Estado contrata una empresa privada para realizar actividades de exploración y explotación, manteniendo la propiedad sobre los recursos extraídos, recibiendo la empresa petrolera una retribución: 0, (iii) Cualquier otra modalidad contractual debidamente aprobada por el Ministerio de Energía y Minas ("MINEM").

Los contratos suscritos bajo cualquier de estos regímenes ofrecen una serie de beneficios, incluyendo la inalterabilidad de los regímenes cambiarios y tributarios vigentes a la fecha de celebración del correspondiente contrato de hidrocarburos.

3 Ver Texto Único Ordenado de la Ley Orgánica de Hidrocarburos, aprobado por Decreto Supremo 042-2005-EM, publicado el 14 de octubre de 2005. 
Los contratos antes detallados pueden celebrarse, previa negociación directa o por concurso. Sin embargo, en ambos casos, para iniciar la negociación de un contrato, el potencial contratista (que puede ser una empresa nacional o extranjera) deberá estar previamente calificado por PERUPETRO. En el caso de las empresas extranjeras, éstas deben establecer una sucursal o constituir una sociedad peruana, fijar domicilio en la capital del Perú y nombrar mandatario de nacionalidad peruana. Una vez aprobados y suscritos los contratos de hidrocarburos solo podrán ser modificados por acuerdo escrito entre las partes, previa aprobación por Decreto Supremo refrendado por el MINEM y el Ministerio de Economía y Finanzas.

El marco regulatorio de las actividades en el upstream incluye el Reglamento de Calificación de Empresas Petroleras (Decreto Supremo 030-2004-EM), el Reglamento de las actividades de Exploración y Explotación de Hidrocarburos (Decreto Supremo 032-2004-EM), la Ley 29875, Ley de Consulta Previa y el Reglamento de Protección Ambiental para las actividades de hidrocarburos (Decreto Supremo 39-2014-EM).

(ii) Reglas del "Downstream": procesamiento, transporte, distribución y comercialización

Tal como hemos indicado previamente, promover la inversión privada en la industria de hidrocarburos en el Perú fue uno de los principales objetivos cuando se configuró la regulación de las actividades "downstream" en 1993. En ese sentido, empresas privadas nacionales o extranjeras pueden ser titulares u operadoras de refinerías, plantas de procesamiento, infraestructura de ductos y almacenamiento y establecimientos de venta al público de hidrocarburos.

A fin de desarrollar las actividades de refinación, procesamiento, almacenamiento, transporte (diferente a ductos) y operación de estaciones de venta al público de hidrocarburos, las empresas requieren lo siguiente: (i) obtener una autorización (informe técnico favorable aprobado por OSINERGMIN) previo al inicio de la etapa constructiva; (ii) estar inscrito en el Registro de Hidrocarburos de OSINERGMIN previo al inicio de sus operaciones comerciales; $y$, adicionalmente para realizar actividades de transporte terrestre y almacenamiento de hidrocarburos en ciertas zonas del país, (iii) estar inscrito en el Registro para el Control de Bienes Fiscalizados de la SUNAT.

A su turno, las actividades de transporte de hidrocarburos y distribución de gas natural por red de ductos solamente pueden ser desarrolladas por las empresas titulares de una concesión otorgada por el MINEM.

Los títulos o autorizaciones antes explicadas pueden resumirse de la siguiente manera:

(a) Transporte por red de ductos: concesión otorgada por el MINEM;

(b) Distribución de gas natural: concesión otorgada por el MINEM;

(c) Refinación: informe técnico favorable y registro otorgado por OSINERGMIN; 
Imaginando una nueva industria de hidrocarburos para el Perú: una mirada "no convencional" y alternativa del sector.

(d) Almacenamiento y transporte (diferente a ductos): informe técnico favorable y registro otorgado por OSINERGMIN;

(e) Establecimientos de Venta al Público: informe técnico favorable y registro otorgado por OSINERGMIN; y,

(f) Compra y manipulación (uso): registro otorgado por SUNAT.

El marco regulatorio de las actividades "downstream" incluye el Reglamento para la Comercialización de Combustibles Líquidos y otros productos derivados de los Hidrocarburos (Decreto Supremo 045-2001-EM); el Reglamento de Comercialización de GLP (Decreto Supremo 01-94-EM); Reglamento de Refinación y Procesamiento de Hidrocarburos (Decreto Supremo 051-93-EM); el Reglamento de Transporte de Hidrocarburos por Ductos (Decreto Supremo 081-2007-EM); el Reglamento de Distribución de Gas Natural por Red de Ductos (Decreto Supremo 42-99-EM ${ }^{4}$ ); el Reglamento de Seguridad en las Actividades de Hidrocarburos (Decreto Supremo 0432007-EM); y, el Reglamento para la Protección Ambiental en las Actividades de Hidrocarburos (Decreto Supremo 039-2014-EM).

\subsection{Reglas de Segunda Generación: Ley de Promoción del Desarrollo de la I ndustria del Gas Natural y su reglamentación.}

Con ocasión de la decisión de la major Shell de retirarse en 1998 de la explotación de las reservas probadas de gas natural descubiertas en Camisea, se decidió llevar a cabo ciertas reformas para afirmar las nuevas bases del desarrollo de los hidrocarburos, enfocadas en impulsar la creación de una nueva industria de gas natural ${ }^{5}$.

Al respecto, en 1999, el Estado peruano aprobó la Ley 27133, Ley de Promoción del Desarrollo de la Industria del Gas Natural, que establece los mecanismos para la entrega a particulares de las reservas probadas de gas natural y aprueba un mecanismo de ingresos garantizados para operadores de redes de transporte y distribución de gas natural.

De manera complementaria a la referida Ley 27133, se aprobaron una serie de regulaciones estableciendo beneficios e incentivos para incrementar el uso de gas natural en diversos sectores de la economía, como el vehicular, residencial e industrial. Con respecto a la generación de energía, un número de reglas fueron también aprobadas a favor de la transformación de turbinas de diesel a gas natural y la entrada de generadores térmicos de gas natural, exceptuándolas temporalmente de la

Cuyo TUO ha sido aprobado por Decreto Supremo 040-2008-EM.

5 Una nueva industria de gas natural de manera masiva para Lima y Callao, diferente a las existentes en ese momento en las ciudades de Talara y Ucayali. 
obligación de proporcionar garantías financieras para obtener autorizaciones y ciertas facilidades para el despacho económico de energía eléctrica.

El Estado aprobó también una serie de mecanismos de promoción específicos tendentes a alentar la explotación y desarrollo de las reservas probadas de gas natural del Lote 88 en Camisea (Cusco) y con estos incrementar el consumo masivo de gas natural en Lima y Callao; incluyendo entre otros: (i) Precios tope para el mercado nacional (por ejemplo: 1.00 US\$/MMBTU (millones de BTU ${ }^{6}$ ) para fines energéticos y 1.80 US\$/MMBTU para otros fines); (ii) un mecanismo de ingresos garantizados para financiar el transporte y distribución a Lima y Callao de gas natural producido en el Lote 88, la denominada Garantía por Red Principal o GRP; y, (iii) beneficios adicionales para consumidores iniciales que suscriban contratos con cláusulas "take or pay" (tomar o pagar), a fin de asegurar parte de los flujos necesarios para la bancabilidad de un proyecto como el Proyecto Camisea (el mayor proyecto de producción de gas natural vigente en el Perú).

\subsection{Reglas de Tercera Generación: Leyes para promover el desarrollo de la industria de gas natural licuefactado (GNL) y la industria petroquímica.}

En el año 2004, como parte de las medidas para promover la industria de gas natural y facilitar el financiamiento de proyectos para explotar estos hidrocarburos, se aprobaron una serie de normas específicas para impulsar el desarrollo de la industria de GNL y su exportación. Estas reglas o normas incluyeron la posibilidad del exportador de GNL de adquirir gas natural del Lote 88 que no sea utilizado para satisfacer el mercado interno.

La industria de GNL en el Perú se rige por el marco jurídico para el desarrollo de gas natural (Ley 27133) y también por la Ley 28176, Ley de Promoción de la Inversión en Plantas de Procesamiento de Gas Natural y su Reglamento (aprobado por Decreto Supremo 031-2004-EM) ${ }^{7}$.

De conformidad con el marco jurídico antes citado, el Estado facilita y otorga ciertos beneficios a los titulares de plantas de procesamiento de gas natural, a fin de promover el desarrollo de la infraestructura asociada a estas plantas y garantizar la libre disponibilidad de los GNL para su exportación. El contrato-ley ha sido la modalidad contractual escogida por nuestra regulación para otorgar estos beneficios al titular de la planta de procesamiento o exportador. Resulta pertinente señalar que, de acuerdo a lo establecido expresamente en el artículo 62ำ de la Constitución del Perú, los contratos-ley no pueden ser modificados por leyes u otras disposiciones de

$6 \quad$ British Thermal Unit (BTU).

7 El desarrollo de proyectos del mercado de GNL en el territorio peruano no se rige por este marco jurídico, ya que el consumo que esta actividad representa es considerado para el mercado doméstico. 
Imaginando una nueva industria de hidrocarburos para el Perú: una mirada "no convencional" y alternativa del sector.

cualquier clase. Este tipo de contratos únicamente puede ser modificado por las partes contratantes.

Los beneficios e incentivos otorgados en virtud de este marco jurídico incluyen, entre otros, los siguientes: (i) Estabilidad del régimen tributario y de los procedimientos correspondientes con el fin de aplicarlo. Adicionalmente, todo el sistema tributario vigente a dicha fecha también se estabiliza; (ii) Posibilidad de obtener una devolución anticipada del Impuesto General a las Ventas (IGV) incurrido durante la fase de construcción; (iii) Libre disponibilidad de los LNG obtenidos en la planta de procesamiento y la posibilidad de que su exportación esté exenta de impuestos en su totalidad; (iv) Suspensión de los deberes de importación durante los primeros dos años; (v) Estabilidad del régimen cambiario, que implica la libre disponibilidad, posesión, uso y disposición de la moneda extranjera; y, (vi) Facilidades para imponer derechos de uso, servidumbre y expropiación de terrenos públicos y privados que puedan ser necesarios para el desarrollo de una planta de procesamiento y el transporte por red de ductos asociado (Ducto Principal ${ }^{8}$ ) .

En los años 2007 y 2008, se aprobaron medidas de promoción adicionales para el desarrollo de la industria de gas natural. En esta ocasión, las medidas aprobadas tienen por finalidad incentivar el desarrollo de una industria petroquímica del etano (plásticos) y metano (fertilizantes y explosivos). Nos referimos a la Ley 29163, Ley de Promoción para el Desarrollo de la Industria Petroquímica (aprobada en el 2007) y su Reglamento aprobado con Decreto Supremo 066-2008-EM (aprobado en el 2008). De conformidad con estas normas, el desarrollo de la industria petroquímica fue declarado de interés nacional y necesidad pública y el suministro de gas natural fue considerado de máxima prioridad para esta industria, luego de ser atendidos los siguientes sectores: domiciliario, hospitales, vehículos, y servicios públicos.

El debate en la aprobación de las Reglas de Tercera Generación fue (y lo ha sido en determinados momentos con más intensidad) entre la necesidad de promover una industria de gas natural (que incluyó su criogenización y exportación como LNG) y la necesidad de garantizar el suministro de gas natural al mercado interno ${ }^{9}$.

La discusión antes referida ha llevado al Estado, el exportador de GNL y los productores del lote 88 a re-negociar los términos del Contrato de Licencia del Lote 88,

8 Término que está definido en el Reglamento de Transporte de Hidrocarburos, aprobado por Decreto Supremo 081-2007-EM.

$9 \quad$ Al respecto, una posición sostiene que debe respetarse el marco legal establecido previamente a suscribirse el Contrato de Licencia del Lote 88 que forma parte integrante del contrato de suministro de gas suscrito con el exportador, por lo que debe preferirse el abastecimiento del mercado interno. La otra posición sostiene que el contrato suscrito con el exportador para el abastecimiento de gas destinado a la exportación es totalmente válido y se suscribió al amparo del Plan Referencial publicado por el MINEM; por lo tanto, ahora dicho contrato debe respetarse. 
a efectos de liberar las reservas de dicho lote que inicialmente fueron comprometidas para la exportación. Así, los compromisos de gas para la exportación se encontrarían actualmente cubiertos con moléculas de gas provenientes de otros lotes.

\subsection{Reglas de Cuarta Generación: Ley que crea el Sistema de Seguridad Energética en Hidrocarburos (SISE) y el Fondo de Inclusión Social Energético (FISE) y Ley de Afianzamiento de la Seguridad Energética vía la construcción de redes de ductos estratégicos.}

En el año 2012, confirmando la política energética relativa a fomentar la masificación del uso de gas natural y acceso universal a una energía más barata y ambientalmente amigable, se aprobó la Ley 29852, Ley que crea el Sistema de Seguridad Energética en Hidrocarburos y el Fondo de Inclusión Social Energético y su Reglamento con Decreto Supremo 021-2012-EM. Las referidas normas marcan un nuevo hito en la regulación de la industria de hidrocarburos, al crear los siguientes mecanismos de intervención económica (subsidios cruzados), y tienen por finalidad brindar seguridad energética al país ${ }^{10}:$

(i) El Sistema de Seguridad Energética en hidrocarburos (SISE): Que permitirá la construcción de redes de ductos para el transporte e instalaciones de almacenamiento de hidrocarburos, consideradas estratégicas por el MINEM para asegurar el abastecimiento de energía en el país; y,

(ii) El sistema o fondo de compensación social energética (FISE): Que facilita el acceso de gas natural y balones de GLP para personas de bajos recursos que identificadas y reconocidas por el Estado. De acuerdo con la página web de este fondo ${ }^{11}$, el FISE es un fondo de inclusión social y se crea con el propósito de llevar energía menos contaminante a poblaciones más vulnerables en todo el país, a través de tres fines: (i) La masificación del gas natural para viviendas y vehículos; (ii) La ampliación de la frontera energética utilizando energías renovables; y, (iii) La promoción para el acceso al GLP (balones de gas doméstico) en los sectores vulnerables urbanos y rurales. Los fondos del FISE se obtienen de: (i) Los grandes consumidores de electricidad ${ }^{12}$; (ii) los usuarios del servicio de transporte de gas natural (Gas de Camisea); y, (iii) la demanda de hidrocarburos líquidos. Con el dinero recaudado del FISE puede llevarse a cabo la

10 Cfr. Exposición de Motivos del Decreto Supremo 021-2012-EM.

11 Cfr. www.fise.gob.pe.

12 Los usuarios libres de electricidad, cuya demanda máxima anual sea mayor a 2,500 kW o en un rango de $200 \mathrm{~kW}$ y $2,500 \mathrm{~kW}$ pero han optado por declararse usuarios libres ante OSINERGMIN. 
ejecución de sus tres fines y también financiar proyectos energéticos adicionales, promovidos por el MINEM.

En el mismo año 2012, mediante la Ley 29970, Ley que afianza la seguridad energética y promueve el desarrollo de polo petroquímico en el sur del país y su reglamentación (Decretos Supremo 005-2014-EM y 014-2014-EM), el Estado estableció reglas complementarias a las establecidas en la Ley 29852 para reafirmar la seguridad energética ${ }^{13}$.

Estas nuevas regulaciones se enfocaron en promover y desarrollar un sistema de red de ductos integrado, construido desde la Planta de Malvinas (ubicada en Camisea) al Sur del Perú ("Sistema Integrado de Transporte"), el cual debe ser capaz de operar en paralelo con los sistema de red de ductos existentes en cierta zona específica determinada por el MINEM ("Zona de Seguridad Energética"), a fin de incrementar la confiabilidad y seguridad en el servicio de transporte a los usuarios de gas natural nacionales.

A continuación describimos los tramos y sistemas que forman parte del Sistema Integrado de Transporte, al que se refieren las normas y que ya ha sido otorgado en concesión:

\section{Cuadro № 1}

\section{Tramos y sistemas del Sistema I ntegrado de Transporte}

\begin{tabular}{|c|c|c|}
\hline Zona & Tramo & Sistema \\
\hline $\begin{array}{c}\text { Zona de } \\
\text { Seguridad } \\
\text { Energética }\end{array}$ & Tramo A1 & $\begin{array}{c}\text { Sistema de Transporte de } \\
\text { Gas Natural ("STG") }\end{array}$ \\
\cline { 2 - 2 } & Tramo B -Gasoducto & \\
\cline { 2 - 3 } & Tramo B -Poliducto & $\begin{array}{c}\text { Sistema de Transporte de } \\
\text { Líquidos ("STL") }\end{array}$ \\
\hline Macro Región Sur & Tramo A2 & $\begin{array}{c}\text { Gaseoducto Sur Peruano } \\
\text { ("GSP") }\end{array}$ \\
\hline
\end{tabular}

Excepto por los costos que los concesionarios no lleguen a cubrir con los ingresos esperados anuales de sus usuarios ("IGA"), los costos de la infraestructura de red de ductos instalada en la Zona de Seguridad Energética será pagada por la demanda beneficiada de gas natural y de los líquidos derivados de hidrocarburos (tarifa de seguridad y cargos SISE) y todos los usuarios de electricidad regulados y libres (a

13 Cfr. Exposición de Motivos del Decreto Supremo 005-2014-EM. 
través del pago de recargos en el suministro de electricidad llamado Cargo por Afianzamiento de la Seguridad Energética o CASE). Tanto la tarifa como el recargo antes mencionados deberán ser aprobados por OSINERGMIN conforme con los procedimientos establecidos para tal fin.

El referido esquema tarifario del Sistema Integrado de Transporte es resumido a continuación en el siguiente cuadro:

\section{Cuadro № 2}

\section{Esquema tarifario del Sistema I ntegrado de Transporte}

\begin{tabular}{|c|c|c|c|c|}
\hline Sistema & Tramo & $\begin{array}{l}\text { Servicios que } \\
\text { se remuneran }\end{array}$ & $\begin{array}{c}\text { Concepto que } \\
\text { cubre el } \\
\text { déficit del } \\
\text { Ingreso } \\
\text { Garantizado } \\
\text { Anual (I GA) }\end{array}$ & $\begin{array}{c}\text { Quiénes } \\
\text { asumen el } \\
\text { pago de los } \\
\text { conceptos } \\
\text { que cubren el } \\
\text { déficit de I GA }\end{array}$ \\
\hline STG & $\begin{array}{l}\text { Tramo A1 } \\
\text { Tramo B - } \\
\text { Gasoducto }\end{array}$ & $\begin{array}{l}\text { Servicio de } \\
\text { Seguridad }^{14} \text { y } \\
\text { Servicio de } \\
\text { Transporte } \\
\text { Adicional }^{15}\end{array}$ & CASE $^{16}$ & $\begin{array}{c}\text { Demanda } \\
\text { beneficiada de } \\
\text { electricidad. }\end{array}$ \\
\hline STL & $\begin{array}{l}\text { Tramo B- } \\
\text { Poliducto }\end{array}$ & $\begin{array}{c}\text { Servicio de } \\
\text { Seguridad y } \\
\text { otros servicios } \\
\text { de transporte }\end{array}$ & SISE $^{17}$ & $\begin{array}{c}\text { Demanda } \\
\text { nacional } \\
\text { hidrocarburos } \\
\text { líquidos. }\end{array}$ \\
\hline GSP & Tramo A2 & $\begin{array}{l}\text { Servicio de } \\
\text { Transporte }^{18}\end{array}$ & CASE & $\begin{array}{c}\text { Demanda } \\
\text { beneficiada de }\end{array}$ \\
\hline
\end{tabular}

14 Es el servicio de transporte por ductos mediante el cual se incrementa la confiabilidad del sistema y continuidad del suministro de Gas Natural y/o Líquidos de Gas Natural.

15 Servicio de Transporte que pueda ser requerido por el concesionario de transporte existente en el STG o usuarios del GSP.

16 Es el cargo por Afianzamiento de la Seguridad Energética.

17 Es el cargo por el Sistema de Seguridad Energética de Hidrocarburos.

18 Servicio público prestado por el concesionario que le permite recibir, transportar por ductos y entregar un volumen de hidrocarburos determinado a través del sistema de transporte. 


\begin{tabular}{|l|c|c|c|c|}
\hline Sistema & Tramo & $\begin{array}{c}\text { Servicios que } \\
\text { se remuneran }\end{array}$ & $\begin{array}{c}\text { Concepto que } \\
\text { cubre el } \\
\text { déficit del } \\
\text { Ingreso } \\
\text { Garantizado } \\
\text { Anual (I GA) }\end{array}$ & $\begin{array}{c}\text { Quiénes } \\
\text { asumen el } \\
\text { pago de los } \\
\text { conceptos } \\
\text { que cubren el } \\
\text { déficit de I GA }\end{array}$ \\
\hline & & & & electricidad. \\
\hline
\end{tabular}

\section{La importancia de la industria de los hidrocarburos en el desarrollo local y su situación actual.}

\subsection{El impacto de los hidrocarburos en la seguridad energética y la economía del país.}

A nuestro juicio, si existe un aspecto en el cual todos los gobiernos han concordado en los últimos años, éste es que para mantener una estabilidad económica y geopolítica es primordial asegurar el suministro de energía para la población y para la industria.

La industria de hidrocarburos tiene una notoria y primordial participación en los siguientes aspectos de un país:

(i) Seguridad Energética: una estrategia o política adecuadas para el aprovechamiento de este recurso natural permitirá a los países cubrir su demanda interna de hidrocarburos, actual y futura, con producción local y sin necesidad de importar de otros países (independencia energética); y,

(ii) Aspectos Económicos: Los hidrocarburos son un recurso importante para las economías de los diferentes países del mundo. Su escasez (por una declinación real en su producción o un previsible agotamiento de reservas) genera tensiones en la economía de un país, sin perjuicio de exacerbar otras tensiones en las agendas geopolíticas de países productores o grandes consumidores como las presentadas anteriormente en el siglo XX.

En la arena local, el primero de estos aspectos relativo a la seguridad energética, es difícil de medir o percibir por todos los ciudadanos. Sin embargo, consideramos que la manera más fácil y directa para percibir un concepto tan abstracto como "seguridad energética", sería imaginarnos nuestros días sin los siguientes energéticos: (i) combustibles en los grifos (gasolinas, petróleo, GLP) ${ }^{19}$; (ii) electricidad en el hogar y en el trabajo ${ }^{20} ; \mathrm{y}$, (ii) gas natural en nuestros hogares e industrias.

19 En el caso particular de los hidrocarburos, en los últimos años el consumo interno se ha caracterizado por una demanda creciente de GLP en el mercado residencial, del diesel, y 
Nadie podría realizar la mayoría de sus actividades domésticas, ni movilizarse a sus centros de estudio o de trabajo. Nótese que muchas de nuestras actividades domésticas y/o procesos productivos en las industrias requieren de energía. Por ejemplo, para la cocción de alimentos, calentar agua, el encendido y funcionamiento de computadoras y otros equipos, la generación de calor para un horno que forma parte del proceso productivo de una industria o para la generación eléctrica. Sería un caos total, que tendría un impacto en nuestra economía familiar, ya que aumentarían significativamente los precios -por sobrecostos en la producción y transporte- de los bienes y servicios que adquirimos de manera diaria y, así de manera acumulada, en la economía del país (inflación).

Con relación al aspecto económico, en esta sección nos remitimos a las cifras brindadas por la Sociedad Peruana de Hidrocarburos, en su reciente estudio "Impacto del Sector Hidrocarburos en la Economía del Perú", cuyos datos - a nuestro juicio más relevantes- los resumimos a continuación:

(a) La participación de los hidrocarburos en el PBI es de S/. 12,333 millones al 2013, apreciándose un incremento de S/. 7,616 millones a S/. 12,330 millones, lo cual representa un incremento de $62 \%$ entre el 2008 al 2013. Siendo el valor acumulado generado por este sector para el periodo 2008-2013 de S/. 63,000 millones;

(b) Las regalías de hidrocarburos representan S/. 5,218 millones frente a S/. 502 millones de regalías mineras al 2013, lo cual indica que las regalías petroleras son diez (10) veces mayores a las del sector minero en dicho año. Siendo las regalías acumuladas del sector de hidrocarburos para el periodo 2003-2013 un total de S/. 33,656 millones, es decir siete (7) veces superiores a las regalías mineras para el mismo periodo;

(c) La participación de los hidrocarburos en el fisco del Estado ha sido de $6 \%$ de la recaudación anual por impuesto a la renta, distribución de dividendos e IGV, siendo de $9.1 \%$ en caso concreto del impuesto a la renta de tercera categoría. El ingreso tributario por este sector fue de S/. 4,445 millones en el 2012; y,

turbo A1 en el sector transporte. Lamentablemente, esta demanda creciente está acompañada de un estancamiento de las inversiones en la actividad de refinación, lo que ha generado una dependencia a la importación del diesel.

20 Según estudios del MINEM, el acceso a la energía eléctrica ha registrado avances significativos desde los años 90. Así, de acuerdo a sus cifras la cobertura eléctrica promedio nacional pasó de $57 \%$ (1993) a $71 \%$ (2003) y ha llegado a alcanzar el $91 \%$ (2013). Ver Plan Energético Nacional 2014-2025, p. 7 y 8 : http://www.minem.gob.pe/minem/archivos/2ResEje-2014-2025\% 20Vf.pdf. 
(d) Los ingresos por canon petrolero y gasífero constituyen un ingreso sustancial para regiones como Tumbes, Piura, Loreto, Ucayali y Cusco, siendo en esta última región hasta el $84.4 \%$ de sus ingresos corrientes en el 2013.

A estos hechos podría añadirse los siguientes. En el sector de hidrocarburos existen actualmente más de 70 empresas directamente involucradas, aproximadamente, y es una fuente importante de puestos de trabajo, directos e indirectos ${ }^{21}$.

\subsection{Situación actual de los hidrocarburos en el Perú. Producción declinante en líquidos y crecimiento de demanda (líquidos y gas natural).}

De acuerdo con el informe de la British Petroleum ("BP") titulado "Statistical Review of World Energy 2014", el consumo de hidrocarburos líquidos (petróleo crudo) en el Perú se incrementó en $150 \%$ en el período comprendido entre los años 2003 a 2013. Más específicamente, en el 2013, el consumo de petróleo ascendió a 224 miles barriles por día (MBD).

El incremento antes descrito puede apreciarse en el siguiente gráfico:

\section{Cuadro № 3}

\section{Consumo de petróleo en Perú}

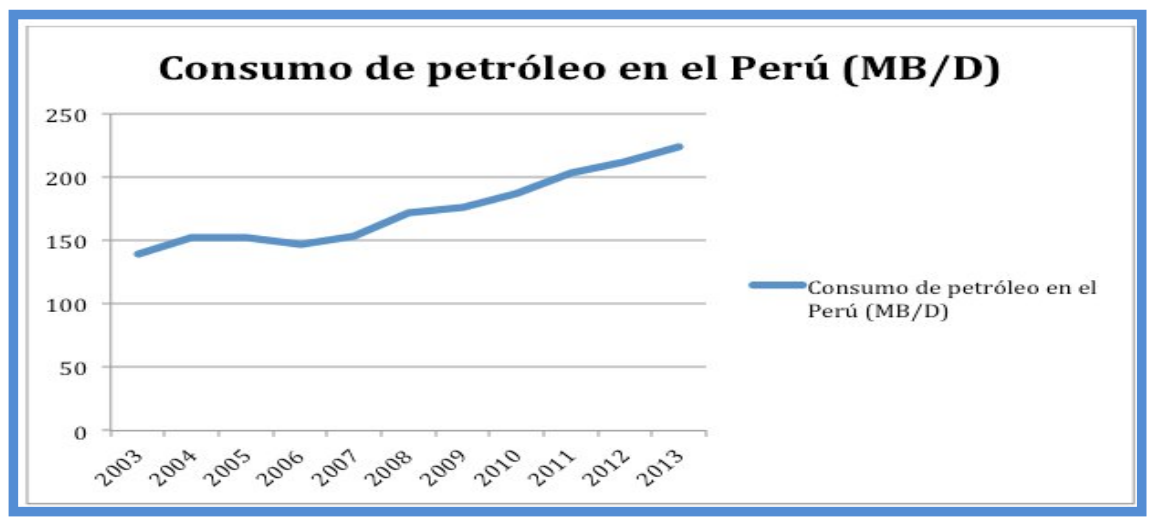

Fuente: BP Statistical Review of World Energy 2014

El creciente consumo de petróleo en el Perú se enfrenta a una producción declinante. Esta afirmación encuentra respaldo en los resultados publicados en el Boletín Estadístico Anual 2014 de la Organización de Países Exportadores de Petróleo (OPEP), el cual indica que la producción de petróleo en el Perú se ha reducido en un $12.5 \%$ entre los años 2009 a 2013, conforme se aprecia en el siguiente cuadro:

$21 \quad$ No es fácil encontrar cifras del total de puestos de trabajo generados por la industria de hidrocarburos, pero el personal involucrado directa e indirectamente en el desarrollo de proyectos de hidrocarburos es un número bastante importante. 


\section{Cuadro № 4}

\section{Producción de petróleo en el Perú (en MBD) ${ }^{22}$}

\begin{tabular}{|c|c|c|c|c|}
\hline 2009 & 2010 & 2011 & 2012 & 2013 \\
\hline 71.8 & 72.6 & 69.6 & 66.6 & 62.8 \\
\hline
\end{tabular}

Fuente: Boletín Estadístico Anual OPEP (Elaboración propia)

En el 2013, como podrá apreciarse de los datos hasta acá consignados, la producción interna de petróleo fue de 62.8 MBD mientras que el consumo local de dicho hidrocarburo fue de $224 \mathrm{MBD}$. Es decir, en dicho año hubo un desacople entre la producción y el consumo de 160 MBD aproximadamente. Para cubrir este déficit, Perú importa la cantidad necesaria restante de petróleo para procesar o mezclar en sus refinerías.

Distintos son los resultados de las reservas probadas de petróleo ${ }^{23}$, las cuales contrariamente a nuestra capacidad de producción- se han incrementado en aproximadamente 40\% entre los años 2009 a 2013, conforme se aprecia a continuación:

\section{Cuadro № 5}

\section{Reservas probadas de petróleo (millones de barriles)}

\begin{tabular}{|c|c|c|c|c|}
\hline 2009 & 2010 & 2011 & 2012 & 2013 \\
\hline 530.9 & 582 & 579.2 & 632.9 & 741.2 \\
\hline
\end{tabular}

Fuente: Libro de Reservas de Hidrocarburos 2009 a 2013 (Elaboración propia)

Entre otros datos igualmente relevantes, en el referido Libro Blanco de los Hidrocarburos, la Sociedad Peruana del Petróleo aborda el tema del desfase entre la capacidad de producción y las reservas probadas de hidrocarburos. Al respecto, ha indicado que "existe una brecha entre lo que se tiene y la capacidad para

22 OPEP, Boletín Estadístico Anual, Viena, Junio 2014, p. 33.

23 "RESERVAS PROBADAS

Cantidades de Hidrocarburos estimadas a una fecha determinada, cuya existencia está demostrada con una certeza razonable por información geológica y de ingeniería, y que pueden ser recuperadas bajo las condiciones económicas, métodos de operación y regulaciones gubernamentales vigentes". Cfr. Decreto Supremo 032-2002-EM, que aprueba el Glosario, Siglas y Abreviaturas del Subsector Hidrocarburos. 
Imaginando una nueva industria de hidrocarburos para el Perú: una mirada "no convencional" y alternativa del sector.

aprovecharlo. Es decir, no se están aprovechando (explotando) las reservas que muy probablemente tenemos" 24 .

Esta ineficiencia en el aprovechamiento de los recursos de hidrocarburos está costándole al Perú una inversión anual significativa en la importación de petróleo crudo para satisfacer una creciente demanda interna. Sobre el particular, según la Sociedad Peruana de Hidrocarburos, el Perú ha importado aproximadamente US $\$ 20,000$ millones en petróleo y sus derivados (Diesel 2, gasolinas y GLP) entre los años 2008 a 2013.

Las importaciones son realizadas a precios internaciones del crudo. Consecuentemente, a nuestro juicio, el contexto internacional de caída de los precios del barril de petróleo - que si bien es cierto nos beneficia en el corto plazo- no puede marcar la pauta de nuestra política energética de mediano ni lago plazo.

Históricamente, la tendencia de los precios internaciones del petróleo es cíclica y, según algunos expertos, los niveles de precios actuales se recuperarían en el mediano plazo. En nuestra opinión, el contexto de precios bajos del barril de petróleo que hoy tenemos y obedece a una combinación de factores económicos, políticos y económicos, debe ser visto por nuestras autoridades como el "periodo de transición" para el Perú. Es decir, un período que estábamos esperando y en el cual deberíamos trabajar intensamente para atraer más inversiones e incrementar gradualmente nuestra producción de petróleo local (actualmente en 62 MBD) para llegar a cubrir nuestra demanda (actualmente de 224 MBD y con tendencia a incrementarse). Al respecto, cabe señalar que, en agosto de 2015, nuestra producción podría caer en aproximadamente 13 MBD por la eminente terminación del Contrato de Licencia del Lote $I A B$ y la falta de convocatoria del proceso de licitación y su correspondiente adjudicación.

Hay que tener en cuenta que nuestra demanda es dinámica y, según los reportes internacionales arriba indicados, crecerá en el corto y largo plazo, momento en el cual ya no nos encontraremos en el mismo contexto internacional de precios bajos, por lo que es imperativo crear una estrategia ahora para buscar promover nuestras actividades del "upstream".

Para mayor información sobre las ratios de la producción versus consumo de petróleo en el Perú, resulta ilustrativo remitirnos al reporte elaborado por la Sociedad Peruana de Hidrocarburos, titulado "Libro Blanco de los Hidrocarburos".

\subsection{Una preocupante realidad. Empresas petroleras están declarando sus contratos bajo fuerza mayor y, en el peor de los casos, retornándolos al Estado}

24 Sociedad Peruana de los Hidrocarburos, Libro Blanco de los Hidrocarburos, Lima, marzo de 2014 , p. 28. 
Enfrentados a reducciones importantes en los presupuestos de exploración, demoras burocráticas y un marcado entorno de conflictividad social, muchos inversionistas petroleros están viéndose obligados a declarar sus contratos bajo fuerza mayor $y$, en casos más extremos, han decido terminarlos y retornarlos al Estado.

La situación anterior, al final de todo, significará un incremento en la brecha existente entre producción y consumo que hemos resaltado.

Al respecto, de conformidad con el Informe Mensual de Actividades de Diciembre 2014, elaborado por PERUPETRO, seis (6) contratos para la exploración y explotación de hidrocarburos fueron terminados en el 2014. De este número total, cuatro (4) por haber permanecido más de doce (12) meses bajos los efectos de fuerza mayor, conforme al detalle que se muestra a continuación:

\section{Cuadro № 6}

\section{Contratos de Hidrocarburos terminados en 2014}

\begin{tabular}{|c|c|c|c|c|}
\hline Empresa/Consorcio & Lote & $\begin{array}{c}\text { Fecha de } \\
\text { Suscripción }\end{array}$ & $\begin{array}{l}\text { Último día } \\
\text { de } \\
\text { vigencia }\end{array}$ & Motivo \\
\hline $\begin{array}{l}\text { Repsol Exploración } \\
\text { Perú, Sucursal del Perú } \\
\text { (70\% ) / Ecopetrol del } \\
\text { Perú S.A. (30\%) }\end{array}$ & 109 & 16.12 .2005 & 10.02 .2014 & $\begin{array}{l}\text { El Contratista decidió } \\
\text { resolver el Contrato al } \\
\text { haber permanecido } \\
\text { más de } 12 \text { meses en } \\
\text { situación de Fuerza } \\
\text { Mayor, lo cual impidió } \\
\text { ejecutar las } \\
\text { obligaciones } \\
\text { establecidas en el } \\
\text { Programa Mínimo de } \\
\text { Trabajo. }\end{array}$ \\
\hline $\begin{array}{l}\text { Pluspetrol E\&P S.A. } \\
\text { (70\% ) / Korea National } \\
\text { Oil Corporation, } \\
\text { Sucursal del Perú } \\
(30 \%)\end{array}$ & 115 & 13.12 .2005 & 12.04 .2014 & $\begin{array}{l}\text { El Contratista decidió } \\
\text { resolver el Contrato al } \\
\text { haber permanecido } \\
\text { más de } 12 \text { meses en } \\
\text { situación de Fuerza } \\
\text { Mayor, lo cual le ha } \\
\text { impedido ejecutar las } \\
\text { obligaciones } \\
\text { establecidas en el 2do } \\
\text { periodo del Programa } \\
\text { Mínimo de Trabajo. }\end{array}$ \\
\hline
\end{tabular}




\begin{tabular}{|c|c|c|c|c|}
\hline $\begin{array}{c}\text { Kedcom Co. Ltd., } \\
\text { Sucursal del Perú } \\
(90 \%) / \text { Compañía } \\
\text { Consultora de Petróleo } \\
\text { S.A. (10\%) }\end{array}$ & 160 & 16.04 .2009 & 30.05 .2014 & $\begin{array}{l}\text { El Contratista decidió } \\
\text { resolver el Contrato al } \\
\text { haber permanecido } \\
\text { más de } 12 \text { meses en } \\
\text { situación de Fuerza } \\
\text { Mayor, lo cual le ha } \\
\text { impedido ejecutar las } \\
\text { obligaciones } \\
\text { establecidas en el } 2 \text { do } \\
\text { periodo del Programa } \\
\text { Mínimo de Trabajo. }\end{array}$ \\
\hline $\begin{array}{c}\text { Grupo Petróleo } \\
\text { Suramericano S.A.C. } \\
(100 \%)\end{array}$ & 156 & 16.04 .2009 & 11.09 .2014 & $\begin{array}{l}\text { El Contratista decidió } \\
\text { resolver el Contrato al } \\
\text { haber permanecido } \\
\text { más de } 12 \text { meses en } \\
\text { situación de Fuerza } \\
\text { Mayor, lo cual le ha } \\
\text { impedido ejecutar las } \\
\text { obligaciones } \\
\text { establecidas en el ler } \\
\text { periodo del Programa } \\
\text { Mínimo de Trabajo. }\end{array}$ \\
\hline Vetra Perú S.A.C. & $X X V$ & 21.11 .2007 & 11.12 .2014 & $\begin{array}{l}\text { El Contratista tomó la } \\
\text { decisión de hacer la } \\
\text { Suelta Total de Área } \\
\text { de Contrato de } \\
\text { Licencia - Lote XXV } \\
\text { durante el Tercer } \\
\text { Periodo de la Fase de } \\
\text { Exploración, debido a } \\
\text { los resultados } \\
\text { negativos, luego de la } \\
\text { perforación de los } \\
\text { pozos Exploratorios } \\
\text { Vicente } 1 X \text { y Valeria } \\
\text { 1X. }\end{array}$ \\
\hline $\begin{array}{l}\text { Pacific Status Energy } \\
\text { S.A., Sucursal del Perú }\end{array}$ & 138 & 21.11 .2007 & 17.12 .2014 & $\begin{array}{l}\text { El Contratista tomó la } \\
\text { decisión de hacer la } \\
\text { Suelta Total de Área } \\
\text { de Contrato de } \\
\text { Licencia - Lote } 138 \\
\text { durante el Segundo }\end{array}$ \\
\hline
\end{tabular}




\begin{tabular}{|l|l|l|}
\hline & $\begin{array}{l}\text { Periodo de la Fase de } \\
\text { Exploración, debido a } \\
\text { los resultados } \\
\text { negativos de luego de } \\
\text { la perforación del } \\
\text { pozor Exploratorio } \\
\text { YAHUISH 1X. }\end{array}$ \\
\hline
\end{tabular}

Fuente: Informe Mensual de Actividades diciembre 2014 PERUPETRO S.A. (Elaboración Propia).

Según estos resultados, salvo por los contratos correspondientes a los lotes XXV y 138, las empresas petroleras decidieron resolver los contratos al haber permanecido más de doce (12) meses en situación de fuerza mayor, lo cual impidió ejecutar las obligaciones establecidas en los correspondientes programas mínimos de trabajo e inversión que estaban garantizadas con cartas fianzas de sumas elevadas y esto generaba costos financieros altos para mantenerlas.

De acuerdo a la información brindada en los informes mensuales anteriores elaborados por PERUPETRO, la situación de fuerza mayor de estos contratos está relacionada con "aspectos sociales" (lote $156^{25}$ y lote $115^{26}$ ) y/o la "elaboración" y/o la "aprobación" del instrumento de gestión ambiental (lote $160^{27}$ y lote $109^{28}$ ).

A los seis contratos terminados en el 2014, podrían sumarse otros veintiocho (28) contratos que actualmente se encuentran con obligaciones suspendidas por situación de fuerza mayor a la fecha, conforme con información de PERUPETRO a Enero 2015 y que resumimos en la siguiente tabla:

\section{Cuadro № 7}

\section{Contratos de Hidrocarburos bajo fuerza mayor en 2015}

\footnotetext{
25 Informe Mensual de Actividades de agosto de 2014.

26 Informe Mensual de Actividades de marzo de 2014.

27 Informe Mensual de Actividades de abril de 2014.

28 Informe Mensual de Actividades de diciembre de 2013.
} 


\begin{tabular}{|c|c|c|c|}
\hline No. & Operador & Lote & Motivo \\
\hline 1 & $\begin{array}{l}\text { Hydrocarbon Exploration PLC, } \\
\text { Sucursal del Perú }\end{array}$ & 183 & $\begin{array}{c}\text { TdR y PPC (presentación, } \\
\text { levantamiento de observaciones } \\
\text { y aprobación) }\end{array}$ \\
\hline 2 & Savia Perú S.A. & Z-45 & $\begin{array}{l}\text { Imposibilidad de realizar } \\
\text { actividades previas que se } \\
\text { requieren para elaborar el } \\
\text { Instrumento Ambiental }\end{array}$ \\
\hline 3 & Savia Perú S.A. & Z-51 & $\begin{array}{l}\text { Imposibilidad de realizar } \\
\text { actividades previas que se } \\
\text { requieren para elaborar el } \\
\text { Instrumento Ambiental }\end{array}$ \\
\hline 4 & Savia Perú S.A. & Z-52 & $\begin{array}{l}\text { Imposibilidad de realizar } \\
\text { actividades previas que se } \\
\text { requieren para elaborar el } \\
\text { Instrumento Ambiental }\end{array}$ \\
\hline 5 & Pluspetrol E\&P S.A. & 102 & $\begin{array}{l}\text { Imposibilidad de realizar } \\
\text { actividades previas que se } \\
\text { requieren para elaborar el } \\
\text { Instrumento Ambiental }\end{array}$ \\
\hline 6 & $\begin{array}{l}\text { Petróleos del Perú - Petroperú } \\
\text { S.A. }\end{array}$ & 64 & $\begin{array}{l}\text { Imposibilidad de realizar } \\
\text { actividades previas que se } \\
\text { requieren para elaborar el } \\
\text { Instrumento Ambiental }\end{array}$ \\
\hline 7 & $\begin{array}{l}\text { BPZ Exploración y Producción } \\
\text { S.R.L. }\end{array}$ & XXIII & $\begin{array}{l}\text { Imposibilidad de realizar } \\
\text { actividades previas que se } \\
\text { requieren para elaborar el } \\
\text { Instrumento Ambiental }\end{array}$ \\
\hline 8 & $\begin{array}{l}\text { Pan Andean Resources PLC } \\
\text { (Perú), Sucursal del Perú }\end{array}$ & 161 & $\begin{array}{c}\text { Aprobación Instrumento } \\
\text { Ambiental }\end{array}$ \\
\hline 9 & $\begin{array}{l}\text { BPZ Exploración y Producción } \\
\text { S.R.L. }\end{array}$ & XXII & $\begin{array}{c}\text { Aprobación Instrumento } \\
\text { Ambiental }\end{array}$ \\
\hline 10 & $\begin{array}{l}\text { CEPSA Perú S.A., Sucursal del } \\
\text { Perú }\end{array}$ & 130 & $\begin{array}{c}\text { Aprobación Instrumento } \\
\text { Ambiental }\end{array}$ \\
\hline 11 & Tecpetrol Lote 174 S.A.C. & 172 & $\begin{array}{c}\text { Aprobación Instrumento } \\
\text { Ambiental }\end{array}$ \\
\hline 12 & Gold Oil Perú S.A.C. & $X X I$ & $\begin{array}{c}\text { Aprobación Instrumento } \\
\text { Ambiental }\end{array}$ \\
\hline 13 & $\begin{array}{l}\text { Petrolífera Petroleum del Perú } \\
\text { S.A.C. }\end{array}$ & 133 & $\begin{array}{c}\text { Aprobación Instrumento } \\
\text { Ambiental }\end{array}$ \\
\hline 14 & CNPC Perú S.A.C. & 58 & $\begin{array}{c}\text { Aprobación Instrumento } \\
\text { Ambiental }\end{array}$ \\
\hline
\end{tabular}




\begin{tabular}{|c|l|c|c|}
\hline $\mathbf{1 5}$ & $\begin{array}{l}\text { BPZ Exploración y Producción } \\
\text { S.R.L. }\end{array}$ & XIX & $\begin{array}{c}\text { Permisos posteriores a la } \\
\text { aprobación de Instrumento } \\
\text { Ambiental }\end{array}$ \\
\hline $\mathbf{1 6}$ & $\begin{array}{l}\text { Pacific Stratus Energy S.A., } \\
\text { Sucursal del Perú }\end{array}$ & 137 & Aspectos sociales \\
\hline $\mathbf{1 7}$ & Savia Perú S.A. & XXVI & Aspectos sociales \\
\hline $\mathbf{1 8}$ & Siboil del Perú S.A. & 105 & Aspectos sociales \\
\hline $\mathbf{1 9}$ & KEI PTY LTD., Sucursal del Perú & 144 & Aspectos sociales \\
\hline $\mathbf{2 0}$ & Gran Tierra Energy S.R.L. & 123 & Aspectos sociales \\
\hline $\mathbf{2 1}$ & Gran Tierra Energy S.R.L. & 129 & Aspectos sociales \\
\hline $\mathbf{2 2}$ & $\begin{array}{l}\text { Olympic Perú Inc., Sucursal del } \\
\text { Perú }\end{array}$ & XIII & Aspectos sociales \\
\hline $\mathbf{2 3}$ & Savia Perú S.A. & Z-6 & Aspectos sociales \\
\hline $\mathbf{2 4}$ & $\begin{array}{l}\text { Talisman Petrolera del Perú, B.V., } \\
\text { Sucursal del Perú }\end{array}$ & 103 & Otros motivos \\
\hline $\mathbf{2 5}$ & $\begin{array}{l}\text { Compañía Consultora de Petróleo } \\
\text { S.A. }\end{array}$ & 100 & Otros motivos \\
\hline $\mathbf{2 6}$ & KEl PTY LTD., Sucursal del Perú & Z-38 & Otros motivos \\
\hline $\mathbf{2 7}$ & $\begin{array}{l}\text { CEPSA Perú S.A., Sucursal del } \\
\text { Perú }\end{array}$ & 114 & Otros motivos \\
\hline $\mathbf{2 8}$ & Gold Oil Perú S.A.C. & Otros motivos \\
\hline
\end{tabular}

Fuente: Informe Mensual de Actividades Enero 2015 PERUPETRO S.A.

Elaboración: PERUPETRO S.A.

El panorama es preocupante de acuerdo con esta tabla. Vemos que las obligaciones de veintiocho (28) contratos de hidrocarburos están suspendidas por fuerza mayor. De esta cantidad, quince (15) basan la fuerza mayor en la "elaboración y/o aprobación" del instrumento ambiental, ocho (8) están fundamentados en "aspectos sociales" y los cinco (5) restantes están fundamentados en "otros motivos" distintos a los anteriores.

Ante ello, en nuestra opinión, el Estado debe tomar medidas inmediatas para revertir esta situación y evitar que se perjudiquen las opciones del Perú de incrementar su producción interna de petróleo con la terminación de estos contratos bajo fuerza mayor.

Sobre las trabas que enfrentan las empresas petroleras y las medidas que podrían tomarse para superarlas nos pronunciamos a continuación.

\section{IV. ¿Qué trabas enfrentan las empresas petroleras en Perú?}

Si bien el Perú ha avanzado significativamente en los últimos años para convertirse en un país con importantes reservas probadas de gas natural y petróleo crudo, que le 
Imaginando una nueva industria de hidrocarburos para el Perú: una mirada "no convencional" y alternativa del sector.

permitirían abastecer la demanda interna de dichos hidrocarburos, el sector de hidrocarburos enfrente una cruda realidad que lo conduce a una casi inexistente actividad exploratoria y una cada vez más declinante actividad de producción (explotación).

No cabe duda que la situación anterior afecta directamente la competitividad del sector de hidrocarburos e, indirectamente, ponen en "jaque" los otros sectores económicos del país y el sueño de alcanzar la independencia energética (seguridad energética).

En el Libro Blanco de los Hidrocarburos, la Sociedad Peruana de Hidrocarburos recopila una serie de trabas que enfrenta el sector, de las cuales consideramos a como las más significativos a las siguientes:

(a) Excesivo tiempo que se requiere para gestionar y obtener autorizaciones para explorar, explotar y luego producir hidrocarburos, siendo las autorizaciones ambientales las que toman más tiempo. La existencia de una excesiva burocracia que genera la denominada "tramitología".

(b) Contexto de conflictividad social en el cual se puede ver inmersa. Escenario de negociaciones constantes con poblaciones locales. Falta de una política de prevención de conflictos sociales consolidada en el Perú.

(c) Mal direccionamiento de la política energética del Estado. La Política Energética Nacional 2010-2040 contiene únicamente cuatro lineamientos de política, de un total de cincuenta y cuatro, que hacen referencia a los hidrocarburos de forma tangencial (ni uno trata el problema del petróleo de forma directa).

(d) Recurrente inestabilidad política que enfrenta el país. A esto se suma el hecho de que un solo Viceministerio se ocupa de diversos sectores (petróleo, gas, electricidad y otras formas de energía), por lo que hace falta una política que visibilice el potencial de la industria de hidrocarburos en el país.

(e) Poca visibilidad de la industria de hidrocarburos en medios de comunicaciones y en líderes políticos y empresariales. Los beneficios de los hidrocarburos no se limitan al aspecto económico, sino al desarrollo de toda la sociedad.

\section{Algunas alternativas "no convencionales": Hacia un cambio que combine una mayor inteligencia política y consolide una visión facilitadora para el desarrollo de la industria.}

En nuestra opinión, el eje central de las trabas del sector de hidrocarburos ha sido abordado y explicado por la Sociedad Peruana de Hidrocarburos. Lo que necesitamos para remontar las trabas existentes en la industria de hidrocarburos es un trabajo en equipo, donde se articulen esfuerzos por parte del Estado, las empresas petroleras y 
las comunidades propietarias de los terrenos donde se encuentran los lotes de hidrocarburos.

La tarea que tenemos para destrabar el sector no es imposible, pero sí requiere de un compromiso tripartito donde planteamos buscar los siguientes objetivos complementarios, a los buscados por la Sociedad Peruana de Hidrocarburos, y que detallamos a continuación:

a. Una cultura orientada al desarrollo de la industria pero con beneficios tangibles hacia su entorno local: Ejecución de obras o trabajos de potenciación del talento local por la empresa petrolera, a su elección, a cuenta del pago de regalías.

Se trataría de un "derecho" a elección de la empresa petrolera y no de una obligación. La idea de este primer objetivo es materializar los beneficios del sector en la población local, vía la construcción directa de obras de infraestructura pública o fomento y capacitación del talento local, a cuenta del pago de regalías. Para tales efectos, pueden establecerse límites al porcentaje de las regalías que pueden destinarse a este tipo de obras o tareas.

La finalidad de este objetivo es tener un mayor enganche de la empresa petrolera con el entorno local, que muchas de sus demandas están asociadas a la implementación de servicios básicos no atendidos no obstante tener recursos provenientes de las regalías. En efecto, las regalías son distribuidas por el gobierno central a los gobiernos regionales y municipalidades. Sin embargo, en la gran mayoría de veces, por falta de capacidad técnica, tales autoridades no logran realizar trabajos tangibles en el entorno local y esto muchas veces llega a enturbiar las relaciones de las empresas petroleras con el entorno local.

Para que el mecanismo que planteamos sea efectivo tendrían que implementarse vías rápidas para la aprobación y ejecución de este tipo de proyectos por PERUPETRO.

b. Una ecuación simple: mayor producción, menor regalía.

Existen varios factores que hacen atractivo un país para ser elegido por las empresas petroleras como destino de inversiones en el sector de hidrocarburos. Por ejemplo, el nivel de intervencionismo estatal en la actividad, la existencia de reservas, la demanda interna, el régimen de regalías o marco fiscal, entre otros. Es frecuente que la apatía de los productores (grandes y pequeños) de invertir en un país, en la mayoría de veces se centre en el marco fiscal. Un país con un porcentaje de regalías elevado no es un destino top. $Y$ será menos atractivo en un contexto internacional de precios bajos del barril de crudo. 
Nuestro régimen de regalías es variado y va desde $5 \%$ hasta $25 \%$ en una escala descendente de producción ${ }^{29}$. Es decir, mientras menor producción, menor el porcentaje de regalías. La empresa petrolera debe optar por una metodología de regalías al momento de efectuar la declaración de descubrimiento comercial de hidrocarburos; luego de lo cual, ya no podrá efectuar cambio de metodología, salvo acuerdo con PERUPETRO.

En este contexto, consideramos que un alternativa a ser incluida como parte de las medidas de impulso para la explotación de hidrocarburos, sería la promoción de una cultura de "mayor producción, menor regalía" en la explotación de petróleo, cuya implementación requerirá re-negociar los contratos de hidrocarburos suscritos que deseen acogerse a esta medida.

Este marco fiscal especial de "mayor producción, menor regalía" permitirá aumentar los niveles de producción de hidrocarburos, sin perjuicio de los ingresos del Estado que se verán incrementados a través de la mayor producción de hidrocarburos, atenuando así el déficit de la balanza comercial y contribuyendo con la reactivación económica del país y de las regiones donde se encuentran los hidrocarburos. De esta manera, se cumplen con los principios generales de promoción e impulso a la industria de hidrocarburos, establecidos en la $\mathrm{LOH}$.

Esta medida sería la equivalente a la medida de establecida en la Ley para la Promoción de la Inversión en la Explotación de Recursos y Reservas Marginales de Hidrocarburos a nivel nacional (Ley $N^{\circ}$ 28109), en virtud de la cual se aprobaron medidas de promoción para la explotación de recursos y reservas marginales de hidrocarburos en el país, con la finalidad de aumentar la producción nacional de hidrocarburos. En líneas generales, los beneficios de la Ley $N^{\circ} 28109$ consistieron en la reducción de la regalía aplicables a las empresa petroleras.

c. Simplificación administrativa e incentivo de la eficiencia en las agencias gubernamentales: Rol facilitador de las inversiones y de prevención de conflictos.

Aunque ya se han dado importantes pasos con los Decretos Supremos 054-2013PCM y 060-2013-PCM, la simplificación administrativa es aún una tarea pendiente. En efecto, según la información publicada por PERUPETRO, la causa común de los contratos de hidrocarburos -que actualmente se encuentran en fuerza mayor- son las demoras en la elaboración y aprobación de la certificación ambiental.

29 Sin considerar a las regalías establecidas por concurso convocado por PERUPETRO, que llegan en algunos casos hasta $37 \%$. En las últimas rondas petroleras convocadas por PERUPETRO, se ha establecido un porcentaje mínimo de $20 \%$ y el factor de competencia es el mayor valor de regalías en adición el valor mínimo de $20 \%$. 
En adición a los cambios a la legislación ambiental en hidrocarburos introducidos por el Reglamento para la Protección Ambiental en las Actividades de Hidrocarburos (Decreto Supremo 039-2014-EM), llamamos la atención de uno de los puntos de la reforma contenida en el denominado "cuarto paquete" reactivador del Ministerio de Economía y Finanzas ${ }^{30}$, consistente en la aprobación de la Certificación Ambiental Integrada. Bajo esta nueva concepción, se integrarían a la aprobación de los estudios de impacto ambiental que actualmente no traen consigo ningún permiso para iniciar obras 0 actividadeslos distintos permisos. Esta figura permitirá destrabar una serie de contratos de hidrocarburos y acelerar el ingreso de nuevos actores al sector de hidrocarburos.

La implementación de la denominada Certificación Ambiental Integrada será una herramienta útil y su implementación tendrá que considerar los siguientes aspectos. La regulación ambiental establece que el estudio ambiental es elaborado sobre la base del proyecto de inversión a nivel de factibilidad (entendida ésta a nivel de ingeniería básica) y la certificación ambiental implica sólo el pronunciamiento sobre la viabilidad ambiental del proyecto.

De conformidad con el TUO de la Ley Orgánica de Hidrocarburos (Decreto Supremo 042-2005-EM) y el Decreto Supremo 030-2004-EM, cualquier inversionista interesado en negociar un contrato para la exploración y/o explotación de hidrocarburos debe estar calificado. El primer paso en este camino de inversión de hidrocarburos es obtener la "calificación como Empresa Petrolera" por parte de PERUPETRO.

En línea con la simplificación administrativa, consideramos que los requisitos para la calificación deben ser reescritos a efectos de incentivar el ingreso de nuevos "players". Así, en adición a la sugerencia brindada por la Sociedad Peruana de Hidrocarburos sobre la modificación de los requisitos para la calificación de empresas petroleras sin experiencia, proponemos como medida la calificación de una empresa petrolera, en función de los siguientes aspectos: (i) capacidad técnica por tipo de lote (por ejemplo, off-shore, on-shore, selva, entre otros); y, (ii) capacidad financiera calculada en Unidades de Trabajo Exploratorio (UTE) globales, la cual podrá ser acreditada incluso con los ingresos de otras empresas pertenecientes al mismo grupo económico. De esta manera, la empresa petrolera obtiene una calificación técnica y financiera global, por tipo de lote y hasta un límite de capacidad financiera, y no lote por lote (área).

La calificación global será modificada cuando la empresa petrolera decida realizar actividades no autorizadas o que demandan mayor capacidad financiera a la que tiene garantizada.

30 Cfr. el Proyecto de Ley 3941/2014-PE del 05 de noviembre de 2014, propone una Ley de promoción de las inversiones para el crecimiento económico y desarrollo sostenible en las zonas de mayor exclusión social. 
El rol facilitador del Estado en las inversiones en términos de simplificación administrativa debe estar acompañado de un liderazgo fuerte y comprometido del Estado para abordar los conflictos sociales existentes y prevenir los futuros.

d. Cambios para atraer nuevos jugadores que también se ocupen de los yacimientos maduros.

En la medida que está próximo el vencimiento de diversos contratos de hidrocarburos con operaciones "maduras" y en una fase declinación de la producción, consideramos que sería importante establecer reglas orientadas a atraer empresas especializadas en operar campos petroleros maduros y que cuenten con tecnologías para extraer las reservas marginales.

El Estado podría celebrar contratos de licencia o servicios con dichas empresas, quienes pagarían una regalía o recibirían una retribución, según corresponda. De esta manera se obtiene un mayor provecho del hidrocarburo que queda en estos lotes.

Conforme con la LOH, al vencimiento de los contratos de licencia, pasan al Estado todos los bienes necesarios para la producción de hidrocarburos. En este sentido, el Estado tendría la opción de suscribir un contrato de servicios con el operador del lote maduro, prorrogar el contrato de licencia o convocar a un nuevo concurso para buscar un nuevo operador. Consideramos que la alternativa del concurso es la que teóricamente presenta mayores opciones de encontrar competencia. Sin embargo, reconocemos que las anteriores alternativas se presentan igual como atractivas en un contexto internacional de precios bajos.

Con independencia de la alternativa que se elija, es importante hacer notar que ésta deberá ser elegida con una anticipación suficiente a la terminación del contrato y así evitar que los lotes maduros en producción corran el riesgo de detener su producción por terminación del plazo, sin haber realizado la prórroga del plazo o la adjudicación a un nuevo operador. Este podría ser el caso del lote IAB cuya licencia vence en agosto de 2015.

e. Incentivar el desarrollo y tecnología para reducir costos de producción.

Como parte del plan de acción del Estado de incentivar las actividades del "upstream", sugerimos contemplar un capítulo importante al desarrollo de nuevas tecnologías para reducir los costos de producción, en aquellas áreas en las que pueda crear ventajas competitivas (tanto off-shore como on-shore).

De este modo, a nuestro juicio, este asunto debería atenderse desde dos aristas: (i) la participación coordinada del Estado con las universidades y empresas de la industria, a fin de crear consorcios tecnológicos; y, (ii) que las nuevas tecnologías sean reconocidas por el Estado como parte de los pagos de las empresas 
petroleras del derecho por transferencia de capacitación y tecnología (CAREC) ${ }^{31}$, esto para crear un incentivo extra a la innovación tecnológica.

\section{Conclusiones}

- De los párrafos anteriores queda clara la importancia que tiene la industria de hidrocarburos en la economía peruana, pues representa una participación importante en los ingresos fiscales del país.

- Resulta claro también que el sector de hidrocarburos presenta trabas y que requieren de una intervención en la regulación por parte del Estado. Las cifras de contratos de hidrocarburos en fuerza mayor y los riesgos de terminación de casi veintiocho (28) contratos de hidrocarburos resultan preocupantes.

- Las principales trabas que enfrenta el sector de hidrocarburos se relacionan básicamente con el excesivo tiempo en la obtención de títulos habilitantes, contexto de conflictividad social, mal direccionamiento de la política energética del Estado, recurrente inestabilidad política; y, poca visibilidad en los medios de comunicación.

- Frente a esta situación, la elaboración de medidas para reducir el déficit de producción del petróleo es inevitable. En ese sentido, en este artículo, proponemos una serie de medidas "no convencionales" y alternativas, entre las cuales destacamos una modificación de la regulación de las regalías, simplificación administrativa y la promoción del desarrollo de nuevas tecnologías para reducir los costos de producción, entre otras. El objetivo es claro: incrementar la producción del petróleo hasta que la oferta interna de este producto y sus derivados nos permita alcanzar una autonomía energética a largo plazo.

- $\quad$ Es claro que estas medidas u otras deben implementarse ahora, a efectos de aprovechar el actual contexto de transición de precios internacionales del petróleo bajos. De lo contrario, el precio internacional del petróleo volverá a subir, y nos encontrará fuera de juego, una combinación letal en términos de desarrollo.

31 Durante la vigencia de los contratos de hidrocarburos, las empresas petroleras están obligadas a efectuar a PERUPETRO las transferencias anuales señaladas en sus respectivos contratos por concepto de capacitación y transferencia de tecnología. 